Desi gn and synt hesi s of novel i midazol i um based i oni c I i qui ds wi th a pseudo crown- et her noi et $y$ : di ast er eomer i c i nt er act $\mathrm{i}$ on of a racemi c i oni c li qui d wi th enant i opure eur opi um compl exes

\begin{tabular}{|l|l|}
\hline 著者 & $\begin{array}{l}\text { I shi da Yasuhi ro, Sasaki Dai suke, M yauchi } \\
\text { H r oyuki, Sai go Kazuhi ko }\end{array}$ \\
\hline $\begin{array}{l}\text { j our nal or } \\
\text { publ i cat i on t i t l e }\end{array}$ & Tet rahedr on Let t er s \\
\hline vol une & 45 \\
\hline number & 51 \\
\hline page r ange & $9455-9459$ \\
\hline year & 2004 12-13 \\
\hline URL & ht t p: //hdl . handl e. net /10173/783 \\
\hline
\end{tabular}




\section{Graphical Abstract}

Design and synthesis of novel imidazolium-based ionic
liquids with a pseudo crown-ether moiety:
diastereomeric interaction of a racemic ionic liquid
with enantiopure europium complexes
Yasuhiro Ishida, Daisuke Sasaki, Hiroyuki Miyauchi, and
Kazuhiko Saigo*
$\begin{aligned} & \text { Department of Chemistry and Biotechnology, Graduate School } \\ & \text { of Engineering, The University of Tokyo }\end{aligned}$
$\begin{aligned} & \text { A planar-chiral imidazolium salt with a tris(oxoethylene) bridge was synthesized, and its potential application as a room- } \\ & \text { temperature ionic liquid with a molecular recognition ability was demonstrated. }\end{aligned}$




\title{
Design and synthesis of novel imidazolium-based ionic liquids with a pseudo crown-ether moiety: diastereomeric interaction of a racemic ionic liquid with enantiopure europium complexes
}

\author{
Yasuhiro Ishida, Daisuke Sasaki, Hiroyuki Miyauchi, and Kazuhiko Saigo* \\ Department of Chemistry and Biotechnology, Graduate School of Engineering, The University of Tokyo, Hongo, Bunkyo-ku, Tokyo 113- \\ 8656, Japan
}

Abstract-A planar-chiral imidazolium salt with a tris(oxoethylene) bridge was synthesized, and its potential application as a roomtemperature ionic liquid with a molecular-recognition ability was demonstrated.

Ionic liquids have attracted much attention as recyclable media for organic synthesis, and their remarkable influences on the selectivity/efficiency of chemical reactions have been demonstrated so far. ${ }^{1}$ Since solutesolvent interaction is one of the most important factors for the control of organic reactions, the development of ionic liquids with a molecular recognition ability is a quite challenging target. For the creation of such ionic liquids, one of the most straightforward approaches is to covalently attach some interactive functionality to conventional molten-salts such as 1,3-dialkyl imidazolium salts. ${ }^{2}$ In order to improve the recognition ability, the threedimensional arrangement of the interactive site(s) should be controlled. However, in the case of the precedent ionic liquids with functional groups, the interactive units were usually placed at the end of a flexible alkyl chain. This is presumably because rigid linkers often bring undesired effects on the physical properties of the salts, such as melting point and viscosity.

Recently, we have proposed a very simple and reliable method for the development of ionic liquids with a molecular recognition ability, giving cyclophane-type imidazolium salts with planar chirality; a well-defined dissymmetric structure was constructed without resorting a rigid/polar substituent, and the salts were proved to realize low melting point, chemical stability, and chiral recognition ability at the same time. ${ }^{3}$ Extending this concept, we here report the synthesis and properties of 'crowned' ionic liquids (1-3), of which the two nitrogens are connected with a tris(oxoethylene) chain. The oligoether units of 1-3 are expected to act as Lewis-basic/hydrogen-accepting functionalities. Furthermore, the relative geometry of the ether units will be fixed owing to the cyclic structure.

Keywords: chiral recognition; crown ether; ionic liquid; planar chirality.

* Corresponding author. Tel.: +81-3-5841-7266; fax:+81-3-5802-3348; e-mail: saigo@chiral.t.u-tokyo.ac.jp
On the basis of our previous work, 'crowned' imidazolium salts (1-3) were designed. ${ }^{3}$ For the preparation of a planarchiral salt 3, we chose 2,4-dimethylimidazole as a fundamental skeleton, of which the nitrogens were connected with a tris(oxoethylene) chain. The resulting salt possesses two essential methyl groups, the C(4) methyl group for the induction of planar chirality and the $\mathrm{C}(2)$ methyl group for the suppression of a rope-skipping process, which results in racemization. The achiral analogues $\mathbf{1}$ and $\mathbf{2}$ were also prepared from imidazole and 2-methylimidazole, respectively. The chloride salts 1a, 2a, and racemic 3a ( $r a c-3 a)$ were synthesized by a procedure

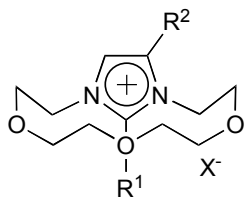

1: $R^{1}=R^{2}=H$

2: $R^{1}=M e, R^{2}=H$

3: $R^{1}=R^{2}=M e$

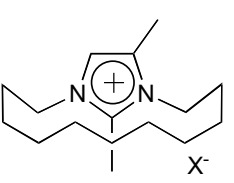

4

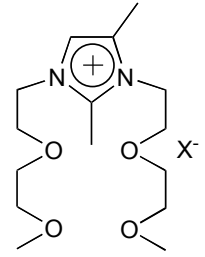

5

$$
\text { a: } \mathrm{X}^{-}=\mathrm{Cl}^{-}(1-3), \mathrm{Br}^{-}(4,5) \quad \text { b: } \mathrm{X}^{-}=\left(\mathrm{CF}_{3} \mathrm{SO}_{2}\right)_{2} \mathrm{~N}^{-}
$$

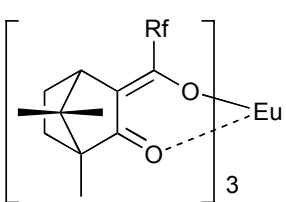

(+)-6: $\mathrm{Rf}=\mathrm{C}_{3} \mathrm{~F}_{7}$

$(+)-7: \mathrm{Rf}=\mathrm{CF}_{3}$

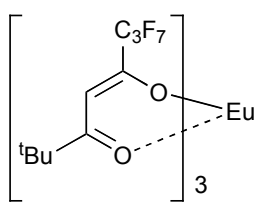

8 similar to that for the preparation of cyclophane-type ionic liquids we have reported (Scheme 1). ${ }^{3,}$ The starting imidazoles were successively treated with sodium hydride and 1,13-dichloro-4,7,10-trioxatridecane to give the corresponding $\mathrm{N}$-substituted imidazoles (60-91\%), which 


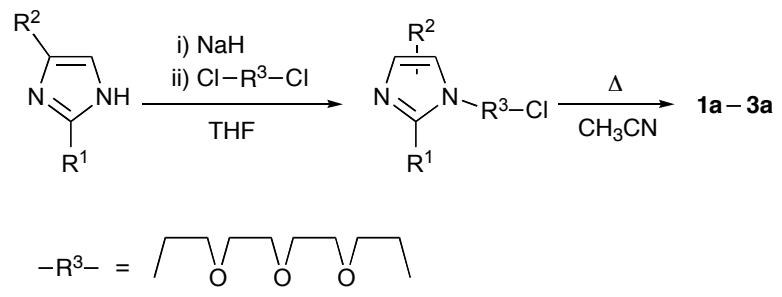

Scheme 1. Synthesis of 1a-3a.

were converted to $\mathbf{1 a}, \mathbf{2 a}$ and rac-3a by intramolecular quaternization.

Unexpectedly, the tris(oxoethylene) group in the bridges showed a favorable effect on the selectivity of the cyclization step. In the case of the alkyl chain-bridged salt 4a, the reaction should be carried out under highly diluted conditions to avoid intermolecular reactions. For example, in the synthesis of racemic $\mathbf{4 a}(\mathrm{rac}-\mathbf{4 a})$, the intermolecular reactions still occurred to generate the undesired oligomers (15-20\%, determined by ${ }^{1} \mathrm{H}$ NMR) even under diluted conditions $(1 \mathrm{mM})$. In sharp contrast, 'crowned' salts were obtained with surprisingly high selectivity; no detectable oligomers were formed at concentrations of 1-100 $\mathrm{mM}$ to give 1a, 2a and rac-3a in good yields (at $100 \mathrm{mM}, 81-$ $82 \%$ ). Thus observed high selectivity for the formation of the 'crowned' imidazolium salts is most likely due to the conformational preference of the tris(oxoethylene) chain; the vicinal oxygens have a strong tendency to take a gauche conformation, and as a result, the tris(oxoethylene) chain is expected to form a curved structure suitable for the intramolecular cyclization. Considering the preparation in a large scale, the selectivity thus observed is quite important. For the synthesis of the 'crowned' salts, the required amount of the solvent is diminished to less than $1 \%$, compared with the formation of the alkyl chainbridged type. In addition, the purification process was highly simplified; in order to isolate rac-4a from the reaction mixture, column chromatography is indispensable, whereas sufficiently pure $r a c-3 a$ was isolated by recrystallization from methanol/ethyl acetate.

The standard anion metathesis method was applied for the exchange of the counter anion of the salts 1a, 2a and rac-3a from chloride to bis(trifluoromethanesulfonyl)imide, which is one of the most widely used anions for the studies of ionic liquids, to afford the corresponding salts $\mathbf{1 b}, \mathbf{2 b}$ and rac-3b (59-89\%). ${ }^{5}$ Although the melting points of $\mathbf{1 b}$ and 2b were not satisfactorily low (melting points: $67{ }^{\circ} \mathrm{C}$ and 82 ${ }^{\circ} \mathrm{C}$, respectively), rac-3b existed as a liquid at room temperature (glass-transition point: $-42{ }^{\circ} \mathrm{C}$ ). The exceptionally low melting point of rac-3b is most likely owing to the dissymmetric structure of the cation part, which is consistent with the case of the alkyl chain-bridged analogues. ${ }^{3}$ In addition, the room temperature ionic liquid rac-3b was immiscible with water, even though the salt possess an amphiphilic unit. Thus observed physical properties of $r a c-3 \mathbf{b}$, low melting point and water immiscibility, are quite notable from the viewpoint of the

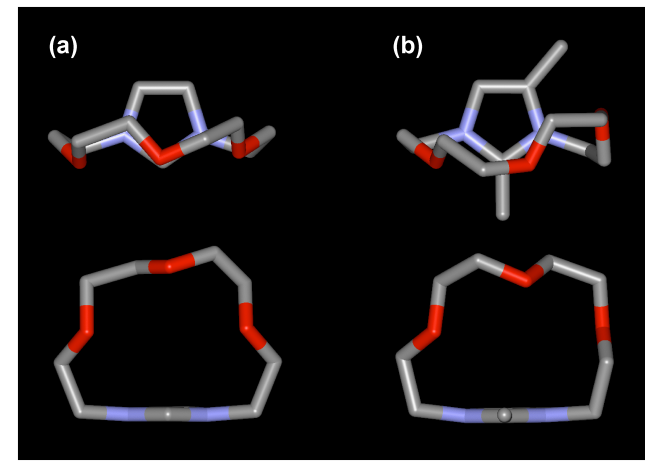

Figure 1. X-ray crystal structure of (a) 1a and (b) rac-3a. Hydrogen atoms, counter anions $\left(\mathrm{Cl}^{-}\right)$, and included solvent molecules $\left(\mathrm{H}_{2} \mathrm{O}\right)$ were omitted for clarity.

practical use of this molten salt for synthesis/separation processes.

Then we investigated about the dynamic profile of the 'crowned' imidazolium salts, focusing on the rope skipping of the bridge through the imidazolium ring. Although the rope-skipping process corresponds to the racemization in the case of planar-chiral $\mathbf{3 a}$, this motion was efficiently suppressed by the steric effect of the $\mathrm{C}(2)$ substituent, which was in good agreement with our previous work. ${ }^{3}$ The ${ }^{1} \mathrm{H}$ NMR measurement of $\mathbf{1 a}$ having no substituent at the $\mathrm{C}(2)$ gave a triplet signal, which is attributable to the methylene protons adjacent to the imidazolium nitrogens. Therefore, the rope skipping of $1 \mathrm{a}$ was concluded to be a fast process so that the geminal protons were not discriminated from each other. Contrary to this, when a methyl group was placed at the $\mathrm{C}(2)$ (2a and 3a), the corresponding methylene protons were observed to be unequivalent to give complicatedly split signals, and furthermore, no sign of coalescence was observed upon elevating the observation temperature to $180{ }^{\circ} \mathrm{C}$. This observation means that the racemization of planar-chiral 3 is not likely to occur under usual conditions.

In order to obtain further information about the structure of 'crowned' imidazolium salts, we carried out the X-ray crystallographic analysis of $\mathbf{1 a}$ and $\mathrm{rac}-\mathbf{3 a} \mathbf{a}^{6}$ As shown in Figure 1, the imidazolium rings were overlaid with the tris(oxoethylene) chain; these structures are consistent with the results of NMR studies as described above. In the case of 1a, the bridge is symmetrical (Figure 1a), whereas that of 3a apparently takes a chiral 'S'-shaped conformation, reflecting the planar chirality of the imidazolium ring (Figure 1b). Noteworthy, no oxygen lone-pair interacts with the imidazolium cation in an intra/intermolecular manner for both 1a and 3a (Figure 1). Although oxoethylene chain $-\pi$ cation interactions are often observed in supramolecular systems, the characteristic cyclic structure of $\mathbf{1 a}$ and $\mathbf{3 a}$ presumably prevented the association of the oxygen lone pairs with the imidazolium cations. 


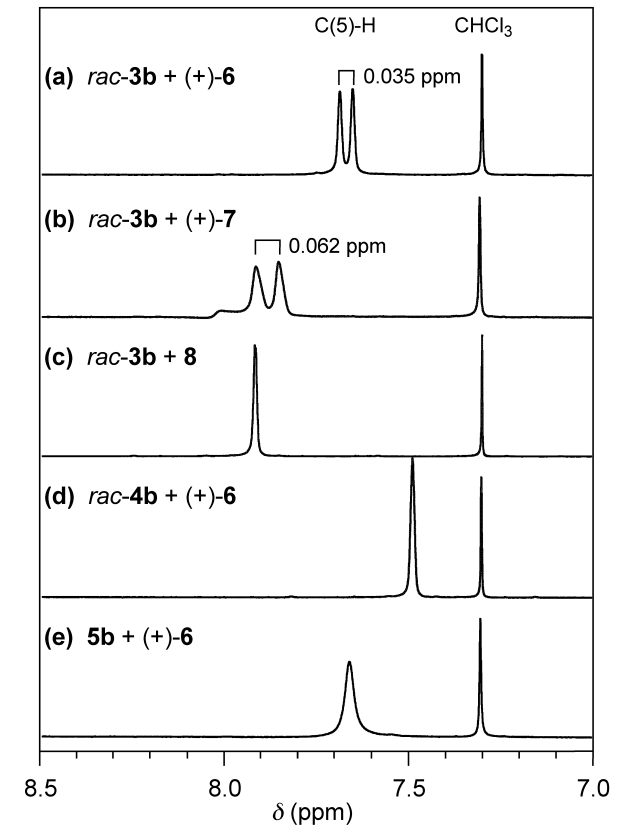

Figure 2. ${ }^{1} \mathrm{H}$ NMR spectra recorded on a Varian Mercury 300 (300 $\mathrm{MHz}$ ) in $\mathrm{CDCl}_{3}$ at $23{ }^{\circ} \mathrm{C}$. Initial concentration: [imidazolium salt $]_{0}=50$ $\mathrm{mM}$, [europium tris $(\beta$-diketonate $)]_{0}=5 \mathrm{mM}$, and [tetraethylammonium chloride $]_{0}=50 \mathrm{mM}$.

The pre-organized arrangement of the free lone pairs in the 'crowned' imidazolium salts motivated us to apply the molten salt rac-3b for molecular recognition. Especially, the recognition of Lewis-acidic substrates is quite interesting, since the development of ionic liquids with Lewis-basic functionalities has been limited to date. ${ }^{2 b}$ As the beginning of the study in this line, we chose enantiopure europium tris $(\beta$-diketonate) complexes $(+)-6$ and $(+)-7$ as the substrates. In the presence of halides $\left(\mathrm{X}^{-}\right)$, europium tris $(\beta$-diketonate) complexes readily form anionic species $\left[\mathrm{Eu}(\beta \text {-diketonate })_{3} \mathrm{X}\right]^{-}$, which have been utilized as NMR shift reagents for organic cations. ${ }^{7}$ The anionic complexes derived from $(+)-6$ and from $(+)-7$ would be suitable to evaluate the molecular recognition ability of $\mathbf{3 b}$, since (i) the anionic europium complexes are expected to accommodate one or two additional ligand(s) so as to avoid relatively unstable hepta-coordinated state ${ }^{8}$ and (ii) these enantiopure complexes might diastereomerically interact with the enantiomers of $\mathbf{3} \mathbf{b}$, which would give more detailed information about the interaction ability of $\mathbf{3 b}$. $^{9}$

As we expected, the enantiomeric imidazolium cations of rac-3b could differently sense the chirality of the europium complexes. When $10 \mathrm{~mol} \%$ of $(+)-6$ or $(+)-7$ was added, for example, to a $\mathrm{CDCl}_{3}$ solution of rac-3b $(50 \mathrm{mM})$ and tetraethylammonium chloride $(50 \mathrm{mM})$, where $[(+)-6-\mathrm{Cl}]^{-}$ or $[(+)-7-\mathrm{Cl}]^{-}$should be generated in situ, the ${ }^{1} \mathrm{H}$ NMR signal of the imidazolium $\mathrm{C}(5)-\mathrm{H}$ split into a set of two singlets (Figures 2a and 2b), and the $\left|\delta_{R}-\delta_{S}\right|$ increased approximately in propotional to the added amount of $(+)-6$ or $(+)-7$. Such splits unequivocally arose from the diastereomeric interaction of $\mathrm{rac}_{-3} \mathbf{3 b}$ with $(+)-6$ or $(+)-7$, since the corresponding signal did not split at all when either of the imidazolium cation or the europium complex was replaced with an achiral analogue. (Figures 2c and 2e). Noteworthy, the tris(oxoethylene) unit gave a crucial effect on the chiral recognition process; in the case of rac-4b without an interactive oligoether unit, the corresponding signal did not split at all under the same conditions (Figure 2d). Although the precise mechanism is still to be investigated, the oxygens in the tris(oxoethylene) unit most likely play a role as an anchor to fix the imidazolium in the complex through the coordination to the europium, since a signal attributed to one of the $\mathrm{OCH}_{2}$ protons showed a notable downfield shift $(\Delta \delta=0.33 \mathrm{ppm} / 0.2$ eq of $(+)-6)$.

In conclusion, we have designed and synthesized novel imidazolium-based ionic liquids $\mathbf{1 b}, \mathbf{2 b}$, and $\mathrm{rac}-\mathbf{3} \mathbf{b}$ with a pseudo crown-ether moiety. Despite their macrocyclic structure, the formation of the chloride salts 1a, 2a and rac3a proceeded efficiently without any highly diluted conditions, owing to the conformational effect of the oligo(oxoethylene) chain. Thus obtained chloride salt rac3a was successfully converted to the room-temperature ionic liquid $r a c-3 \mathbf{b}$. Several analyses revealed that the oxygen lone pairs in 1-3 did not interact with the imidazolium cations, but had a potential as Lewis-basic and/or hydrogen-accepting functionality. The ionic liquid developed here is expected to bring some influence on the efficiency and/or selectivity of the organic reactions conducted in this solvent.

\section{Experimental data}

3a: To a solution of 2,4-dimethylimidazole (3.83 g, 40 $\mathrm{mmol})$ in dry THF $(140 \mathrm{ml})$ under nitrogen atmosphere was added $1.92 \mathrm{~g}$ (48 $\mathrm{mmol})$ of $60 \%$ sodium hydride with a mineral oil. The mixture was stirred for $60 \mathrm{~min}$ at $\mathrm{rt}$, and then 1,13-dichloro-4,7,10-trioxatridecane $(23.5 \mathrm{~mL}, 27.7 \mathrm{~g}$, $120 \mathrm{mmol}$ ) was added to the mixture. The reaction mixture was stirred at $60{ }^{\circ} \mathrm{C}$ for 2 days, whereupon a white solid was depisited. After cooling the mixture to $\mathrm{rt}$, the solid was filtered off, and the filtrate was concentrated under reduced pressure. The residue was subjected to a column chromatography (silica gel, chloroform/methanol) to afford a mixture of 1-(1-chloro-4,7,10-trioxadodecyl)-2,4dimethylimidazole and 1-(1-chloro-4,7,10-trioxadodecyl)2,5-dimethylimidazole $(10.18 \mathrm{~g}, 35 \mathrm{mmol}, 88 \%)$ as a colorless oil. The N-substituted imidazole (12.05 g, 41.4 $\mathrm{mmol})$ thus obtained was dissolved in acetonitrile $(300 \mathrm{~mL})$ and refluxed for 20 days. After being cooled to room temperature, the reaction mixture was concentrated and successively subjected to a column chromatography (silica gel deactivated with $10 \%$ of water, chloroform/methanol) to afford racemic 3a as a white solid $(9.75 \mathrm{~g}, 33.5 \mathrm{mmol}$, $81 \%$ ): IR (KBr): $3450,2875,1620,1460,1360,1310$, $1250,1140,1050,930,840,615 \mathrm{~cm}^{-1}$. ${ }^{1} \mathrm{H} \mathrm{NMR}\left(\mathrm{CDCl}_{3}\right): \delta$ $(\mathrm{ppm})=2.36(3 \mathrm{H}, \mathrm{d}, J=0.9 \mathrm{~Hz}), 2.71(3 \mathrm{H}, \mathrm{s}), 3.28-3.55$ $(7 \mathrm{H}, \mathrm{m}), 3.65-3.74(3 \mathrm{H}, \mathrm{m}), 3.97-4.04(2 \mathrm{H}, \mathrm{m}), 4.24-4.44$ $(3 \mathrm{H}, \mathrm{m}), 4.81-4.86(1 \mathrm{H}, \mathrm{m}), 7.91(1 \mathrm{H}, \mathrm{d}, J=0.9 \mathrm{~Hz})$. FAB-MS: Calcd. for $\mathrm{C}_{13} \mathrm{H}_{23} \mathrm{~N}_{2} \mathrm{O}_{3}[\mathrm{M}]^{+}=255$. Found 255 .

1a: 1-(1-chloro-4,7,10-trioxadodecyl)-imidazole, the 
precursor of 1a, was synthesized from imidazole in the same procedure as that of the precursor of 3a (91\% yield). The N-substituted imidazole was converted to $\mathbf{1 a}$ in the same procedure as that of $\mathbf{3 a}(82 \%)$ : IR (KBr): 3425,2880 , $1580,1450,1350,1120,1100,930,825,760,615 \mathrm{~cm}^{-1} \cdot{ }^{1} \mathrm{H}$ $\mathrm{NMR}\left(\mathrm{CDCl}_{3}\right): \delta(\mathrm{ppm})=3.60-3.63(4 \mathrm{H}, \mathrm{m}), 3.67-3.73$ $(4 \mathrm{H}, \mathrm{m}), 3.93(4 \mathrm{H}, \mathrm{t}, J=4.5 \mathrm{~Hz}), 4.61(4 \mathrm{H}, \mathrm{t}, J=4.5 \mathrm{~Hz})$, $7.96(2 \mathrm{H}, \mathrm{d}, J=1.8 \mathrm{~Hz}), 9.42(1 \mathrm{H}, \mathrm{s})$. FAB-MS: Calcd. for $\mathrm{C}_{11} \mathrm{H}_{19} \mathrm{~N}_{2} \mathrm{O}_{3}[\mathrm{M}]^{+}=227$. Found 227 .

$2 \mathbf{a}$ 1-(1-chloro-4,7,10-trioxadodecyl)-2methylimidazole, the precursor of $\mathbf{2 a}$, was synthesized from 2-methylimidazole in the same procedure as that of the precursor of 3a $(60 \%$ yield). The $\mathrm{N}$-substituted imidazole was converted to $\mathbf{2 a}$ in the same procedure as that of $\mathbf{3 a}$ (81\%): IR (KBr): 3550, 3025, 1530, 1470, 1410, 1290, $1195,1090,1055,875,760,650,550 \mathrm{~cm}^{-1}$. ${ }^{1} \mathrm{H} \mathrm{NMR}$ $\left(\mathrm{CDCl}_{3}\right): \delta(\mathrm{ppm})=2.68(3 \mathrm{H}, \mathrm{s}), 3.27-3.44(6 \mathrm{H}, \mathrm{m}), 3.66-$ $3.74(4 \mathrm{H}, \mathrm{m}), 3.99-4.04(2 \mathrm{H}, \mathrm{m}), 4.24-4.33(2 \mathrm{H}, \mathrm{m}), 4.76-$ $4.82(2 \mathrm{H}, \mathrm{m}), 8.07(2 \mathrm{H}, \mathrm{s})$. FAB-MS: Calcd. for $\mathrm{C}_{12} \mathrm{H}_{21} \mathrm{~N}_{2} \mathrm{O}_{3}[\mathrm{M}]^{+}=241$. Found 241.

3b: To an aqueous solution $(3 \mathrm{~mL})$ of racemic 3a $(146$ $\mathrm{mg}, \quad 0.50 \mathrm{mmol})$ was added lithium bis(trifluoromethylsulfonyl)imide $(147 \mathrm{mg}, 0.50 \mathrm{mmol})$ at $70{ }^{\circ} \mathrm{C}$, and the mixture was stirred for $30 \mathrm{~min}$ at the temperature. The reaction mixture was extracted with $\mathrm{CH}_{2} \mathrm{Cl}_{2}(5 \mathrm{~mL})$, and the organic phase was washed with water $(5 \times 5 \mathrm{~mL})$, then concentrated under reduced pressure. The resultant residue was dried in vacuo at $55{ }^{\circ} \mathrm{C}$ overnight to afford racemic $\mathbf{3 b}(238 \mathrm{mg}, 0.44 \mathrm{mmol}, 89 \%)$ as a colorless oil: Melting point: $T_{\mathrm{g}}=-42{ }^{\circ} \mathrm{C}$ (midpoint of the grass-transition temperature). IR (KBr): $3140,2875,1625$, $1520,1455,1350,1200,1135,1050,930,835,785,735$, $615,565,510 \mathrm{~cm}^{-1}$. ${ }^{1} \mathrm{H}$ NMR $\left(\mathrm{CDCl}_{3}\right): \delta(\mathrm{ppm})=2.31(3 \mathrm{H}$, $\mathrm{d}, J=1.2 \mathrm{~Hz}), 2.64(3 \mathrm{H}, \mathrm{s}), 3.27-3.58(8 \mathrm{H}, \mathrm{m}), 3.65-3.70$ $(2 \mathrm{H}, \mathrm{m}), 3.92-4.00(2 \mathrm{H}, \mathrm{m}), 4.10-4.34(4 \mathrm{H}, \mathrm{m}), 7.07(1 \mathrm{H}$, d, $J=1.2 \mathrm{~Hz}$ ). Elemental analysis: Calcd. for $\mathrm{C}_{15} \mathrm{H}_{23} \mathrm{~F}_{6} \mathrm{~N}_{3} \mathrm{O}_{7} \mathrm{~S}_{2}$ : C, 33.64; $\mathrm{H}, 4.33 ; \mathrm{N}, 7.85$. Found: $\mathrm{C}$, 33.52; H, 4.32; N, 7.80.

1b: 1b was prepared from 1a in the same procedure as that of $\mathbf{3 b}\left(59 \%\right.$ yield): Melting point: $T_{\mathrm{m}}=67{ }^{\circ} \mathrm{C}$. IR (KBr): $3125,2900,1550,1450,1345,1330,1200,1175$, $1120,1050,930,815,750,740,615,570,510 \mathrm{~cm}^{-1} \cdot{ }^{1} \mathrm{H}$ NMR $\left(\mathrm{CDCl}_{3}\right): \delta(\mathrm{ppm})=3.61-3.64(4 \mathrm{H}, \mathrm{m}), 3.68-3.71$ $(4 \mathrm{H}, \mathrm{m}), 3.90(4 \mathrm{H}, \mathrm{t}, J=4.5 \mathrm{~Hz}), 4.37(4 \mathrm{H}, \mathrm{t}, J=4.5 \mathrm{~Hz})$, $7.34(2 \mathrm{H}, \mathrm{d}, J=1.8 \mathrm{~Hz}), 9.25(1 \mathrm{H}, \mathrm{s})$. Elemental analysis: Calcd. for $\mathrm{C}_{13} \mathrm{H}_{19} \mathrm{~F}_{6} \mathrm{~N}_{3} \mathrm{O}_{7} \mathrm{~S}_{2}: \mathrm{C}, 30.77 ; \mathrm{H}, 3.77 ; \mathrm{N}, 8.28$. Found: C, 30.88; H, 3.88; N, 8.03.

2b: $\mathbf{2 b}$ was prepared from $\mathbf{2 a}$ in the same procedure as that of $\mathbf{3 b}(66 \%$ yield $)$ : Melting point: $T_{\mathrm{m}}=82{ }^{\circ} \mathrm{C}$. IR (KBr): 3150, 2910, 1530, 1450, 1350, 1200, 1130, 1050, 930, 830, 750, 670, 565, $510 \mathrm{~cm}^{-1}$. ${ }^{1} \mathrm{H}$ NMR $\left(\mathrm{CDCl}_{3}\right): \delta$ $(\mathrm{ppm})=2.66(3 \mathrm{H}, \mathrm{s}), 3.27-3.46(6 \mathrm{H}, \mathrm{m}), 3.53-3.61(2 \mathrm{H}$, $\mathrm{m}), 3.67-3.71(2 \mathrm{H}, \mathrm{m}), 3.95-4.01(2 \mathrm{H}, \mathrm{m}), 4.23-4.38(4 \mathrm{H}$, $\mathrm{m}), \quad 7.31(2 \mathrm{H}, \mathrm{s})$. Elemental analysis: Calcd. for $\mathrm{C}_{14} \mathrm{H}_{21} \mathrm{~F}_{6} \mathrm{~N}_{3} \mathrm{O}_{7} \mathrm{~S}_{2}$ : C, 32.25; H, 4.06; N, 8.06. Found: C, $32.15 ; \mathrm{H}, 4.24 ; \mathrm{N}, 7.89$.

\section{Acknowledgments}

We acknowledge Prof. Takashi Kato (The University of Tokyo) for use of the DSC equipment. A part of this work was financially supported by a Grants-in-Aid for Young Scientists (No. 14750674) from the Ministry of Education, Culture, Sports, Sciences and Technology, and Japan Interaction in Science and Technology Forum.

\section{References}

1. For reviews, see: (a) Welton, T. Chem. Rev. 1999, 99, 2071; (b) Sheldon, R. Chem. Commun. 2001, 2399; (c)

Wasserscheid, P.; Keim, W. Angew. Chem. Int. Ed. 2000, 39, 3772; (d) Welton, T.; Wasserscheid, P. Ionic liquids in synthesis, Wiley-Interscience: New York, 2003.

2. For selected examples, see: (a) Cole, A. C.; Jensen, J. L.; Ntai, I.; Tran, K. L. T.; Weaver, K. J.; Forbes, D. C.; Davis, Jr., J. H. J. Am. Chem. Soc. 2002, 124, 5962; (b) Handy, S. T.; Okello, M.; Egrie, C.; Dickenson, G.; Proc. Electrochem. Soc. 2002, 19, 257; (c) Handy, S. T.; Okello, M.; Dickenson, G. Org. Lett. 2003, 5, 2513; (d) Wasserscheid, P.; DrießenHölscher, B.; van Hal, R.; Steffens H. C.; Zimmermann, J. Chem. Commun. 2003, 2038.

3. Ishida,Y.; Miyauchi, H.; Saigo, K. Chem. Commun. 2002, 2240.

4. For examples of the investigations on the gauche effect in 1,4-dioxa systems, see: Ganguly, B.; Fuchs, B. J. Org. Chem. 2000, 65, 558, and references cited therein.

5. Bonhôte, P.; Dias, A.-P.; Armand, M.; Papageorgiou, N.; Kalyanasundaram, K.; Grätzel, M. Inorg. Chem. 1996, 35, 1168.

6. Crystal data. 1a: triclinic, $a=10.103, b=10.104, c=$ $15.911 \AA, \alpha=78.729, \beta=78.726, \gamma=62.111^{\circ}$, space group $P$ $-1, Z=2, R_{\text {int }}=0.0860$. rac-3a: triclinic, $a=8.470, b=9.481$, $c=21.110 \AA, \alpha=90.018, \beta=90.072, \gamma=62.111^{\circ}$, space group $P-1, Z=2, R_{\text {int }}=0.0610$. CCDC 242992 and CCDC 242993 contain the supplementary crystallographic data for this paper. These data can be obtained free of charge via www.ccdc.cam.ac.uk/data request/cif, by emailing data_request@ccdc.cam.ac.uk, or by contacting The Cambridge Crystallographic Data Centre, 12 Union Road, Cambridge CB2 1EZ, UK; fax: +44 1223336033.

7. For examples of the lanthanoide-induced shifts of organic salts, see: Wenzel, T. J.; Zaia, J. J. Org. Chem. 1985, 50, 1322, and references cited therein.

8. Kabuto, K.; Sasaki, Y. J. Chem. Soc., Chem. Commun. 1987, 670.

9. For examples of diastereomeric interactions of ionic liquids and chiral substrates, see: (a) Wasserscheid, P.; Bösmann A.; Bolm, C. Chem. Commun. 2002, 200; (b) ref. 3; (c) Levillain, J.; Dubant, G.; Abrunhosa, I.; Gulea, M.; Gaumont, A.-C. Chem. Commun. 2003, 2914; (d) Clavier, H.; Boulanger, L.; Audic, N.; Toupet, L.; Mauduit, M.; Guillemin, J.-C. Chem. Commun. 2004, 1224; (e) Jodry, J. J.; Mikami, K. Tetrahedron Lett. 2004, 45, 4429. 